\title{
THYROID CANCER IN SARDINIAN PEDIATRIC PATIENTS: REPORT OF 63 CASES AND A REVIEW OF THE LITERATURE
}

\author{
L. M. Lai ${ }^{1}$, A. Satta ${ }^{1}$, G. Pinna ${ }^{2}$, L. M. Altana ${ }^{2}$, G. Senes ${ }^{1}$, P. Coni ${ }^{1}$, G. Faa ${ }^{1}$ \\ ${ }^{1}$ Department of Pathology, San Giovanni di Dio University Hospital, AOU Cagliari, University of Cagliari, Cagliari, Italy \\ ${ }^{2}$ Nuova Casa di Cura di Decimomannu, Cagliari, Italy
}

\section{CORRESPONDING AUTHOR:}

Andrea Satta

Department of Pathology

San Giovanni di Dio University Hospital

AOU Cagliari

University of Cagliari

Cagliari, Italy

via Ospedale 46

09124 Cagliari, Italy

E-mail: andreasatta@yahoo.it

ORCID: 0000-0002-7627-9912

Doi: $10.48286 / a r o .2021 .32$

History

Received: Mar 14, 2021

Accepted: Jul 16, 2021

Published: Sept 1, 2021

\section{ABSTRACT}

Thyroid cancer is considered uncommon in pediatrics, yet it is the most common endocrine malignancy among them. The aim of this study was to analyze pediatric thyroid carcinomas diagnosed in Sardinian children and adolescents in order to find a possible association with autoimmune diseases. We studied 63 consecutive 10-20-years-old patients who underwent surgery for thyroid cancer between January 2001 and April 2020 in our hospital.

No evidence of risk factors including external radiation was found. All cases were follicular-derived neoplasms: 45 PTCs (72\%), 9 FTCs (14\%), 2 well differentiated carcinomas not otherwise specified (3\%), 2 poorly differentiated carcinomas (3\%), 5 cases of encapsulated PTC-FV were re-diagnosed as NIFTP
(8\%), according to the last WHO classification. Autoimmune thyroid diseases were detected in the 29 PTCs (64\% of PTCS). BRAF V600E mutation was found in 21 PTCs (47\% of PTCs). Our study shows that thyroid cancer in Sardinian children and adolescents is characterized by peculiar features: our cohort is composed only by Follicular-derived differentiated thyroid cancer without medullary carcinomas; PTC seems to be more frequent and strongly associated with autoimmune thyroid diseases in our population. Those evidences, together with the absence of any exposure to radiation in our patients, support the possibility that autoimmune diseases became an important event to be considered also in the evolution of pediatric thyroid carcinogenesis. 


\section{KEY-WORDS}

Pediatric thyroid carcinomas; BRAF V600E; PTC; autoimmune thyroid diseases.

\section{INTRODUCTION}

Even if differentiated thyroid cancers have always been considered rare in pediatric population $(1,2)$, recently an increasing incidence of thyroid cancer in adults as well as in children and adolescents was reported (3). In the pediatric population, the only consolidated risk factor is the exposure to radiation. The scientific interest on radiation-associated risk of thyroid cancer, increased in pediatric population after the Chernobyl and Fukushima nuclear accident, was extended to radiation exposure regarding therapeutic procedures. In fact, youngest children are more sensitive to radiation-induced carcinogenesis, the minimal latent period for thyroid cancer development after exposure is as short as 4 years and is dose dependent $(1,2)$. The reasons associated with this progressive trend are controversial because the incidence growth of thyroid cancer in children may not be justified only by an increase of radiation risk (4).

Other risk factors are involved in thyroid diseases and, among these, we can distinguish genetic (thyroid disease like autoimmune thyroid disorders) and epigenetic events (iodine nutritional deficiency) (4-7). Even though there is no indication of ethnic or race susceptibility in pediatric thyroid cancer, an increased trend was found in different geographic regions of the United States and some genetic peculiarities associated with this cancer are present in the Sardinian Island population $(8,9)$. In particular, Sardinians are more sensible to autoimmune diseases, strongly associated with papillary thyroid carcinoma (10-12). The recent years have seen an increasing focus on the genes implicated in carcinogenesis, also for the thyroid tumors $(13,14)$. The genetic mutations are important for understanding the nature of the tumors and they have an implication in the therapy and in the follow-up. One of the most important gene mutations on thyroid cancers is the BRAF V600E mutation (15). This mutation, thought to mimic phosphorylation of the activation site (15, 16), is important not only for the prognosis, but also for the therapeutic response. In fact, radioactive

\section{IMPACT STATEMENT}

A twenty-year study with a large number of cases of thyroid cancer in pediatric patients in the particular genetic scenario of Sardinia.

iodine therapy normally has a good response, but its efficacy is variable in BRAF V600E + cases (17). The mutated BRAF V600E protein in fact causes a resistance to iodine absorption, thus making radioactive iodine ineffective $(17,18)$. Recently it was proposed a specific targeted therapy for thyroid cancer (a BRAF inhibitor) used for both, pediatric and adult population, according to the adult guidelines, and thyroid cancer is not classified differently in children compared to young adults (2). All together these data underline that pediatric and adult's thyroid cancer tend to have a different evolution (more advanced disease and an excellent overall survival rate in children and adolescents); however, most of the studies have been performed in radiation-exposed pediatric thyroid carcinoma and there is no clear explanation for these differences. Therefore, there is a strong need for studies in pediatric population and, for this reason, the aim of this study is to analyze 63 Sardinian pediatric clinical cases of thyroid cancer.

\section{PATIENTS AND METHODS}

This retrospective study was approved by the ethics committee of the University Hospital of Cagliari. We examined 63 consecutive cases. All thyroid samples were formalin-fixed and paraffin-embedded. 3-micron thick paraffin sections were stained with Hematoxylin and Eosin for histology. All cases have been reviewed by two experienced pathologists (MLL and AS) and histopathological assessment was performed and re-diagnosed according to the fourth edition of the WHO classification (22). BRAF mutational status was determined using the Diatech Pharmacogenetics piro-sequencing system (Diatech Pharmacogenetics, www/diatechpharmacogenetics.com) performed on formalin-fixed, paraffin-embedded tumor tissues. Neoplastic and non-neoplastic (surrounding) formalin-fixed tissues were microdissected from hematoxy- 
lin-stained thyroid tissue and genomic DNA was extracted using the MagCore Automated Nucleic Acid Purification system (RBC. Bioscience Corp., www/ rbcbiocience.com). For Immunohistochemical analysis, $3 \mu \mathrm{m}$ thick sections were obtained from each paraffin block. All reagents were purchased from Ventana Medical Systems Inc. 1910 E. Innovation Park Drive Tucson, Arizona 85755 USA.

All immunostaining procedures were performed using the UltraView Universal DAB Detection Kit (Ref. 760-5000) on the BenchMark Ultra instrument, according to the manufacturer's instructions.

\section{RESULTS}

The vast majority of cases was incidentally diagnosed by ultrasonography in the setting of a follow-up for a preexisting autoimmune thyroid disease or during screening programs in schoolhouses. At clinical examination, few patients presented a painless or tender thyroid nodule.

No risk factor, including exposure to ionizing radiation or ingestion of radioiodine, was present in any patient's history. No family history of thyroid cancer was reported in our patient's clinical information.

Distant metastases were never detected. At histology all cases were follicular-derived neoplasms (table I). In 58 cases a diagnosis of malignancy was made; 5 cases, already diagnosed as encapsulated follicular variants of papillary thyroid carcinoma, were re-classified as NIFTP (8\%), according to the new classification of the WHO (19). The malignant cases included 45 papillary thyroid carcinomas (PTCS) (72\%), 9 follicular thyroid carcinomas (FTCs)
(14\%), 2 well differentiated carcinomas not otherwise specified (3\%) and 2 poorly differentiated carcinomas with focal areas of differentiated PTC (3\%). PTCs were predominantly observed in females (F/M $=36 / 9$ ), with a median age of 16.8 years (range 10$20 \mathrm{y}) ; 10$ cases were multifocal (22\% of PTCs), 1 presented intravascular invasion (2\% of PTCs) and 25 showed lymph node metastases (55.5\% of PTCs). The extrathyroid invasion was present in 17 PTCS (38\% of PTCs) and 29 were associated with autoimmune thyroid diseases ( $64 \%$ of PTCs).

About the 9 cases of FTCs, 7 were in females and 2 in males, with a median age of 17.7 years, ranging from 13 to 20 years at presentation. In 5 patients, intravascular invasion was detected (55\% of FTCS), but none presented with lymph node metastases. 2 FTCs presented extrathyroid invasion (22\% of FTCS) and 4 were associated with autoimmune thyroid diseases (44\% of FTCS). The 5 patients with NIFTP were all females, with a median age of 17 years old, ranging from 12 up to 20 years old at presentation. None of them were multifocal, nor did they present intravascular invasion or lymph node metastases or extrathyroid invasion, as indeed it must be for the diagnosis of NIFTP. One was associated with autoimmune thyroid diseases.

The two cases of well differentiated carcinomas not otherwise specified (WDC-NOS) were found in a 15 and a 19-years-old patients, (median age $17 \mathrm{y}$ ), respectively a male and a female. 1 of them presented intravascular invasion ( $50 \%$ of WDCs-NOS). None of them were multifocal, nor did they show lymph node metastases or extrathyroid invasion or association with autoimmune thyroid diseases. The two patients with a diagnosis of poorly differentiated carcinoma

\begin{tabular}{|c|c|c|c|c|c|c|c|c|}
\hline HISTOTYPE & $\begin{array}{c}\text { N. } \\
\text { (\% PER } \\
\text { COLUMN) }\end{array}$ & $F / M$ & $\begin{array}{l}\text { MEDIAN } \\
\text { AGE } \\
\text { (RANGE) }\end{array}$ & $\begin{array}{l}\text { MULTIFOCAL } \\
\text { (\% PER ROW) }\end{array}$ & $\begin{array}{c}\text { IVI } \\
\text { (\% PER } \\
\text { ROW) }\end{array}$ & $\begin{array}{l}\text { LN METASTASES } \\
\text { (\% PER ROW) }\end{array}$ & $\begin{array}{l}\text { EXTRATHYROID } \\
\text { INVASION } \\
\text { (\% PER ROW) }\end{array}$ & $\begin{array}{c}\text { ASSOCIATED } \\
\text { AITD } \\
\text { (\% PER ROW) }\end{array}$ \\
\hline PTC & $\begin{array}{c}45 \\
(72 \%)\end{array}$ & $36 / 9$ & $\begin{array}{c}16.8 \\
(10-20 y)\end{array}$ & $\begin{array}{c}10 \\
(22 \%)\end{array}$ & $\begin{array}{c}1 \\
(2 \%)\end{array}$ & $\begin{array}{c}25 \\
(55,5 \%)\end{array}$ & $\begin{array}{c}17 \\
(38 \%)\end{array}$ & $\begin{array}{c}29 \\
(64 \%)\end{array}$ \\
\hline FTC & $\begin{array}{c}9 \\
(14 \%)\end{array}$ & $7 / 2$ & $\begin{array}{c}17.7 \\
(13-20 y)\end{array}$ & $\begin{array}{c}0 \\
(0 \%)\end{array}$ & $\begin{array}{c}5 \\
(55 \%)\end{array}$ & $\begin{array}{c}0 \\
(0 \%)\end{array}$ & $\begin{array}{c}2 \\
(22 \%)\end{array}$ & $\begin{array}{c}4 \\
(44 \%)\end{array}$ \\
\hline NIFTP & $\begin{array}{c}5 \\
(8 \%)\end{array}$ & $5 / 0$ & $\begin{array}{c}17.0 \\
(12-20 y)\end{array}$ & $\begin{array}{c}0 \\
(0 \%)\end{array}$ & $\begin{array}{c}0 \\
(0 \%)\end{array}$ & $\begin{array}{c}0 \\
(0 \%)\end{array}$ & $\begin{array}{c}0 \\
(0 \%)\end{array}$ & $\begin{array}{c}1 \\
(20 \%)\end{array}$ \\
\hline WDC-NOS & $\begin{array}{c}2 \\
(3 \%)\end{array}$ & $1 / 1$ & $\begin{array}{c}17.0 \\
(15-19 y)\end{array}$ & $\begin{array}{c}0 \\
(0 \%)\end{array}$ & $\begin{array}{c}1 \\
(50 \%)\end{array}$ & $\begin{array}{c}0 \\
(0 \%)\end{array}$ & $\begin{array}{c}0 \\
(0 \%)\end{array}$ & $\begin{array}{c}0 \\
(0 \%)\end{array}$ \\
\hline PDC & $\begin{array}{c}2 \\
(3 \%)\end{array}$ & $2 / 0$ & $\begin{array}{c}17.5 \\
(17-18 y)\end{array}$ & $\begin{array}{c}0 \\
(0 \%)\end{array}$ & $\begin{array}{c}2 \\
(100 \%)\end{array}$ & $\begin{array}{c}1 \\
(50 \%)\end{array}$ & $\begin{array}{c}2 \\
(100 \%)\end{array}$ & $\begin{array}{c}2 \\
(100 \%)\end{array}$ \\
\hline
\end{tabular}

Table I. Cases.

PTC: Papillary Thyroid Carcinoma; FTC: Follicular Thyroid Carcinoma; NIFTP: NonInvasive Follicular Thyroid neoplasm with Papillary like nuclear features; WDC-NOS: Well Differentiated Carcinoma - Not Otherwise Specified; PDC: Poorly Differentiated Carcinoma; IVI: IntraVascular Invasion; AITD: Autolmmune Thyroid Disease. 
(PDC) were both females, one 17- and the other 18 years old (median age $17.5 \mathrm{y}$ ). In both cases we found intravascular invasion (100\% of PDCs) and extra-thyroidal extension (100\% of PDCs). In one patient lymph nodal metastases were present (50\% of PDCs). Both patients had autoimmune thyroid diseases (100\% of PDCs). Regarding the subtypes of PTCs (table II), 17 showed features of the Classical Variant (PTC-CV) (38\% of PTCS), 11 were Follicular Variant (PTC-FV) (24\% of PTCS), 8 were diagnosed as Tall Cell variant (PTC-TCV) (18\% of PTCs), 6 as Diffuse Sclerosis variant (PTC-DSV) (13.5\% of PTCs), 2 were diagnosed as Solid Variant (PTC-SV) (4.5\% of PTCS) and 1 as Cribriform variant (PTC-CrV) (2\% of PTCs). The distribution of BRAF V600E mutation in papillary thyroid carcinomas (table III) was found in 21 out of 45 cases (47\%), with a median age of 16.3 years old (range 11-20 years). 7 cases were multifocal (33.3\%), 1 case showed intravascular invasion (5\%), lymph-nodes metastases were present in 13 cases (62\%) and extrathyroid extension in 9 cases (42\%). The BRAF V600E mutation was associated with autoimmune thyroid diseases in
15 out of 21 cases (71\%). BRAF V600E negative PTCs patients had median age 17.4 years old (range 10-20 years), association with autoimmune thyroid disease was found in 14 out of 24 cases (58\%), extra thyroid extension in 8 out of 24 cases (33\%) and lymph-node metastases in 12 out of 24 cases (50\%). No BRAF V600E mutation was found in any cases of FTCs, well differentiated carcinomas not otherwise specified, poorly differentiated carcinomas and NIFTPs.

\section{DISCUSSION}

The trend of the incidence rates for sporadic PTC in childhood and adolescence shows a constant growth (3). The prevalent risk factor for thyroid cancer are the ionizing radiations but other genetic, environmental and lifestyle factors are emerging (20). In fact, an increased proportion of mutations less associated to radiation exposure (BRAF and RAS point mutations) was described in different studies (21-24).

\begin{tabular}{|c|c|c|c|c|c|c|c|c|}
\hline VARIANTS & $\begin{array}{c}\text { N. } \\
\text { (\% PER } \\
\text { COLUMN) }\end{array}$ & F/M & $\begin{array}{l}\text { MEDIAN } \\
\text { AGE } \\
\text { (RANGE) }\end{array}$ & $\begin{array}{l}\text { MULTIFOCAL } \\
\text { (\% PER ROW) }\end{array}$ & $\begin{array}{c}\text { IVI } \\
\text { (\% PER } \\
\text { ROW) }\end{array}$ & $\begin{array}{l}\text { LN METASTASES } \\
\text { (\% PER ROW) }\end{array}$ & $\begin{array}{l}\text { EXTRATHYROID } \\
\text { INVASION } \\
\text { (\% PER ROW) }\end{array}$ & $\begin{array}{c}\text { ASSOCIATED } \\
\text { AITD } \\
\text { (\% PER ROW) }\end{array}$ \\
\hline CV & $\begin{array}{c}17 \\
(38 \%)\end{array}$ & $15 / 2$ & $\begin{array}{c}17.2 \\
(10-20 y)\end{array}$ & $\begin{array}{c}6 \\
(35 \%)\end{array}$ & $\begin{array}{c}0 \\
(0 \%)\end{array}$ & $\begin{array}{c}7 \\
(41 \%)\end{array}$ & $\begin{array}{c}5 \\
(29 \%)\end{array}$ & $\begin{array}{c}13 \\
(76 \%)\end{array}$ \\
\hline FV & $\begin{array}{c}11 \\
(24 \%)\end{array}$ & $9 / 2$ & $\begin{array}{c}18.4 \\
(16-20 y)\end{array}$ & $\begin{array}{c}1 \\
(9 \%)\end{array}$ & $\begin{array}{c}0 \\
(0 \%)\end{array}$ & $\begin{array}{c}3 \\
(27 \%)\end{array}$ & $\begin{array}{c}2 \\
(18 \%)\end{array}$ & $\begin{array}{c}3 \\
(27 \%)\end{array}$ \\
\hline TCV & $\begin{array}{c}8 \\
(18 \%)\end{array}$ & $5 / 3$ & $\begin{array}{c}15.6 \\
(11-19 y)\end{array}$ & $\begin{array}{c}3 \\
(37.5 \%)\end{array}$ & $\begin{array}{c}1 \\
(12,5 \%)\end{array}$ & $\begin{array}{c}8 \\
(100 \%)\end{array}$ & $\begin{array}{c}4 \\
(50 \%)\end{array}$ & $\begin{array}{c}5 \\
(62,5 \%)\end{array}$ \\
\hline DSV & $\begin{array}{c}6 \\
(13.5 \%)\end{array}$ & $4 / 2$ & $\begin{array}{c}16.0 \\
(14-19 y)\end{array}$ & $\begin{array}{c}0 \\
(0 \%)\end{array}$ & $\begin{array}{c}0 \\
(0 \%)\end{array}$ & $\begin{array}{c}6 \\
(100 \%)\end{array}$ & $\begin{array}{c}4 \\
(66,6 \%)\end{array}$ & $\begin{array}{c}6 \\
(100 \%)\end{array}$ \\
\hline SV & $\begin{array}{c}2 \\
(4.5 \%)\end{array}$ & $2 / 0$ & $\begin{array}{c}14.0 \\
(13-15 y)\end{array}$ & $\begin{array}{c}0 \\
(0 \%)\end{array}$ & $\begin{array}{c}0 \\
(0 \%)\end{array}$ & $\begin{array}{c}0 \\
(0 \%)\end{array}$ & $\begin{array}{c}1 \\
(50 \%)\end{array}$ & $\begin{array}{c}1 \\
(50 \%)\end{array}$ \\
\hline $\mathrm{CrV}$ & $\begin{array}{c}1 \\
(2 \%)\end{array}$ & $1 / 0$ & $\begin{array}{l}15.0 \\
(15 y)\end{array}$ & $\begin{array}{c}0 \\
(0 \%)\end{array}$ & $\begin{array}{c}0 \\
(0 \%)\end{array}$ & $\begin{array}{c}1 \\
(100 \%)\end{array}$ & $\begin{array}{c}1 \\
(100 \%)\end{array}$ & $\begin{array}{c}1 \\
(100 \%)\end{array}$ \\
\hline
\end{tabular}

Table II. PTC Variants.

CV: Classic Variant; FV: Follicular Variant; TCV: Tall Cells Variant; DSV: Diffuse Sclerosing Variant; SV: Solid Variant; CrV: Cribriform Variant; IVI: IntraVascular Invasion; AITD: Autolmmune Thyroid Disease.

\begin{tabular}{|c|c|c|c|c|c|c|c|c|}
\hline & $\begin{array}{c}\text { N. } \\
\text { (\% PER } \\
\text { COLUMN) }\end{array}$ & F/M & $\begin{array}{l}\text { MEDIAN } \\
\text { AGE } \\
\text { (RANGE) }\end{array}$ & $\begin{array}{l}\text { MULTIFOCAL } \\
\text { (\% PER ROW) }\end{array}$ & $\begin{array}{c}\text { IVI } \\
\text { (\% PER } \\
\text { ROW) }\end{array}$ & $\begin{array}{l}\text { LN METASTASES } \\
\text { (\% PER ROW) }\end{array}$ & $\begin{array}{l}\text { EXTRATHYROID } \\
\text { INVASION } \\
\text { (\% PER ROW) }\end{array}$ & $\begin{array}{c}\text { ASSOCIATED } \\
\text { AITD } \\
\text { (\% PER ROW) }\end{array}$ \\
\hline $\begin{array}{l}\text { BRAF } \\
\text { V600E } \\
\text { mutated }\end{array}$ & $\begin{array}{c}21 \\
(47 \%)\end{array}$ & $16 / 5$ & $\begin{array}{c}16.3 \\
(11-20 y)\end{array}$ & $\begin{array}{c}7 \\
(33.3 \%)\end{array}$ & $\begin{array}{c}1 \\
(5 \%)\end{array}$ & $\begin{array}{c}13 \\
(62 \%)\end{array}$ & $\begin{array}{c}9 \\
(43 \%)\end{array}$ & $\begin{array}{c}15 \\
(71 \%)\end{array}$ \\
\hline $\begin{array}{l}\text { BRAF } \\
\text { V600E not } \\
\text { mutated }\end{array}$ & $\begin{array}{c}24 \\
(53 \%)\end{array}$ & $20 / 4$ & $\begin{array}{c}17.4 \\
(10-20 y)\end{array}$ & $\begin{array}{c}3 \\
(12.5 \%)\end{array}$ & $\begin{array}{c}0 \\
(0 \%)\end{array}$ & $\begin{array}{c}12 \\
(50 \%)\end{array}$ & $\begin{array}{c}8 \\
(33 \%)\end{array}$ & $\begin{array}{c}14 \\
(58 \%)\end{array}$ \\
\hline
\end{tabular}

Table III. BRAF Mutation in PTCS.

PTC: Papillary Thyroid Carcinoma. 
In any cases, more multicenter studies are necessary to better understand the relevance of different risk factors thyroid carcinogenesis (25).

This study made in Sardinia, a Mediterranea island without any evidence of radiation contamination, in 63 clinical cases without head and neck radiation exposure, represent one of the firsts example of a possible association between pediatric thyroid cancer and autoimmune thyroiditis. This association was more evident in PTC samples (64\% of the cases) but seems to be present also in the 4 out of 9 FTC cases examined (44\%). The presence of autoimmune thyroiditis was already described in adults thyroid cancers, in PTC and even if in reduced frequency also in FTC (26-28), in the general population or in areas with an high prevalence of Hashimoto's disease (11-13, 29-31).

These thyroid cancers have been described as less aggressive and with a better prognosis and more frequent in younger patient. On the contrary, our pediatric PTC samples with autoimmune diseases showed, as all pediatric thyroid tumors, a more aggressive pattern (55,5\% with LF metastasis and $38 \%$ of exstrathyroid invasion), confirming that relevant differences between pediatric and adult thyroid tumor may exist.

In our study, thyroid carcinoma affected more girls than boys, with a 4-fold predominance, in line with more recent studies $(2,3,32,33)$ supporting previous hypotheses on a relevant role played by hormonal determinants in the pathogenesis of thyroid carcinoma $(2,34)$. The median age at diagnosis, in our cohort, was 17 years (ranging from 10 up to 20) different of that observed in others studies (13.514.6-14.7 years) suggesting a possible elderly clinical manifestation in our population $(3,32,33)$.

The relationship between chronic autoimmune thyroiditis and thyroid carcinogenesis are still controversial but seems that they could share the same molecular pathogenesis and therefore, these inflammatory events could be considered as preneoplastic lesions (35-37).

Some studies (38) estimated that the BRAF V600E mutation has a lower incidence in thyroid pediatric cancers than in adults, while other studies reported a higher incidence (38-41). In line with the latter, in our cohort, BRAF V600E mutation was frequently detected (47\% of PTCs). Even if Hardee et al. specify that the BRAF V600E mutation is not associated with a more aggressive clinical course in the pediatric people (41), our and other studies indicated a more aggressive behavior, such as described in adults. Therefore, the relevance of the BRAF V600E mutation seems to be relevant also for the diagnosis of the PTC in the pediatric patients, in particular because is indicative for specific therapy strategies. PTC was the most common histological subtype diagnosed in our children and adolescents, accounting for $70 \%$ of the total. No case of anaplastic/undifferentiated carcinoma was found in our series, confirming the rarity of this entity in young people. In our population, follicular derived differentiated carcinomas represent $100 \%$ of thyroid cancers originating in children and adolescents. This finding contrasts with previous reports, indicating medullary thyroid carcinoma appearing in about $10 \%$ of patients affected by thyroid cancer in childhood, mostly correlated with MEN2B syndrome (42).

\section{CONCLUSIONS}

This study represents one of the first example of pediatric thyroid carcinoma made in a population genetically predisposed to autoimmune diseases. The high percentage of clinical cases associated with autoimmune thyroiditis clearly indicate the opportunity of a screening campaign in these pediatric patients in order to prevent a possible insurgence of this type of cancer and to obtain more diagnostic and therapeutic recommendations. Finally, this and other studies highlights the need to establish a more personalized approach in these clinical cases.

\section{ETHICS}

\section{Fundings}

There were no institutional or private fundings for this article.

\section{Conflict of interests}

The authors have declared no conflict of interests.

\section{Availability of data and material}

All the data supporting the findings of this study are available within the article and can be shared just before a reasonable request to the corresponding author.

\section{Authors' contribution}

All the authors contributed equally to conception, data collection, analysis and writing of this paper. 


\section{REFERENCES}

1. NikiforovYE. Radiation-induced thyroid cancer: what we have learned from chernobyl. Endocr Pathol 2006 Winter;17(4):307-17. Doi:10.1007/ s12022-006-0001-5.PMID:17525478.

2. Stefan Al, Piciu A, Mester A, Apostu D, Badan $\mathrm{M}$, Badulescu $\mathrm{Cl}$. Pediatric Thyroid Cancer in Europe: An Overdiagnosed Condition? A Literature Review. Diagnostics (Basel) 2020;10(2):112. Doi:10.3390/diagnostics 10020112 . PMID:32092888;PMCID:PMC7168245.

3. Paulson VA, Rudzinski ER, Hawkins DS. Thyroid Cancer in the Pediatric Population. Genes (Basel) 2019;10(9):723. Doi:10.3390/genes10090723. PMID:31540418;PMCID:PMC6771006.

4. Boas M, Feldt-Rasmussen U, Skakkebaek NE, Main KM. Environmental chemicals and thyroid function. Eur J Endocrinol 2006;154(5):599611.Doi:10.1530/eje.1.02128.PMID:16645005.

5. Francis GL, Waguespack SG, Bauer AJ, et al. American Thyroid Association Guidelines Task Force. Management Guidelines for Children with Thyroid Nodules and Differentiated Thyroid Cancer. Thyroid 2015;25(7):716-59. Doi:10.1089/ thy.2014.0460.PMID:25900731;PMCID:PMC4854274.

6. Penta L, Cofini M, Lanciotti L, Leonardi A, Principi N, Esposito S. Hashimoto's Disease and Thyroid Cancer in Children: Are They Associated? Front Endocrinol (Lausanne) 2018;9:565. Doi:10.3389/ fendo.2018.00565.PMID:30356680; PMCID:PMC6189282.

7. Zimmermann MB, Galetti V. Iodine intake as a risk factor for thyroid cancer: a comprehensive review of animal and human studies. Thyroid Res 2015;8:8. Doi:10.1186/s13044-015-0020-8. PMID:26146517;PMCID:PMC4490680.

8. Vergamini LB, Frazier AL, Abrantes FL, Ribeiro KB, Rodriguez-Galindo $C$. Increase in the incidence of differentiated thyroid carcinoma in children, adolescents, and young adults: a population-based study.J Pediatr 2014;164(6):1481-5. Doi:10.1016/j. jpeds.2014.01.059.Epub 2014.PMID: 24630354.

9. Delitala AP, Pilia MG, Ferreli L, et al. Prevalence of unknown thyroid disorders in a Sardinian cohort. Eur J Endocrinol 2014;171(1):143-9. Doi: 10.1530/EJE-14-0182.PMID:24917664;PMCID:PMC4527527.

10. Arnaud-Lopez L, Usala G, Ceresini G, et al. Phosphodiesterase 8B gene variants are as- sociated with serum TSH levels and thyroid function. Am J Hum Genet 2008;82(6):1270-80. Doi:10.1016/j.ajhg.2008.04.019.PMID:18514160; PMCID:PMC2427267.

11. Olivieri A, Pinna G, Lai A, et al.; Sardinian Newborn Study Group. The sardinian autoimmunity study. 4. Thyroid and islet cell autoantibodies in sardinian pregnant women at delivery: a cross-sectional study. J Endocrinol Invest 2001;24(8):570-4. Doi:10.1007/BF03343896.PMID:11686538.

12. Meloni A, Mandas C, Jores RD, Congia M. Prevalence of autoimmune thyroiditis in children with celiac disease and effect of gluten withdrawal. J Pediatr 2009;155(1):51-5, 55.e1. Doi: 10.1016/j.jpeds.2009.01.013. Epub 2009 Mar 25.PMID:19324373.

13. Hsiao SJ, Nikiforov YE. Molecular approaches to thyroid cancer diagnosis. Endocr Relat Cancer 2014;21(5):T301-13. Doi: 10.1530/ERC-140166. Epub 2014.PMID:24829266; PMCID:PMC4160369.

14. Yakushina VD, Lerner LV, Lavrov AV. Gene Fusions in Thyroid Cancer. Thyroid 2018;28(2):15867. Doi:10.1089/thy.2017.0318.PMID:29281951.

15. Ritterhouse LL, Barletta JA. BRAF V600E mutation-specific antibody: A review. Semin Diagn Pathol 2015;32(5):400-8. Doi:10.1053/j. semdp.2015.02.010. Epub 2015 Feb 7.PMID: 25744437.

16. Davies H, Bignell GR, Cox C, et al. Mutations of the BRAF gene in human cancer. Nature 2002;417(6892):949-54. Doi:10.1038/nature00766.Epub 2002 Jun 9.PMID:12068308.

17. Fallahi $P$, Ferrari $S M$, Santini $F$, et al. Sorafenib and thyroid cancer. BioDrugs 2013;27(6):615-28. Doi:10.1007/s40259-013-0049-y.PMID: 23818056.

18. Xing $M$, Westra $W H$, Tufano RP, et al. BRAF mutation predicts a poorer clinical prognosis for papillary thyroid cancer. J Clin Endocrinol Metab 2005;90(12):6373-9. Doi:10.1210/jc.20050987.Epub 2005 Sep 20.PMID: 16174717.

19. Chan JKC, Nikiforov YE, Tallini G. Other encapsulated follicular-patterned thyroid tumours. In: Lloyd RV, Osamura RY, Klöppel G, Rosai J (eds) World Health Organization Classification of Tumours of Endocrine Organs. Fourth edition. IARC Press, Lyon, France 2017;75-80.

20. Qian ZJ,Jin MC, Meister KD, Megwalu UC. Pediatric Thyroid Cancer Incidence and Mortality Trends 
in the United States, 1973-2013. JAMA Otolaryngol Head Neck Surg 2019;145(7):617-623. Doi: 10.1001/jamaoto.2019.0898. PMID:31120475;PMCID:PMC6547136.

21. Romei C, Fugazzola L, Puxeddu E, et al. Modifications in the papillary thyroid cancer gene profile over the last 15 years. J Clin Endocrinol Metab 2012;97(9):E1758-65. Doi:10.1210/jc.2012-1269. Epub 2012 Jun 28.PMID: 22745248.

22. Mathur A, Moses W, Rahbari R, et al. Higher rate of BRAF mutation in papillary thyroid cancer over time: a single-institution study. Cancer 2011;117(19):4390-5. Doi:10.1002/cncr.26072. Epub 2011 Mar 15.PMID:21412762;PMCID:PMC3131457.

23. Jung CK, Little MP, Lubin JH, et al. The increase in thyroid cancer incidence during the last four decades is accompanied by a high frequency of BRAF mutations and a sharp increase in RAS mutations. J Clin Endocrinol Metab 2014 Feb;99(2):E276-85. Doi:10.1210/jc.2013-2503. Epub 2013 Nov 18.PMID:24248188;PMCID:PMC3913801.

24. Nikiforov YE, Rowland JM, Bove KE, Monforte-Munoz H, Fagin JA. Distinct pattern of ret oncogene rearrangements in morphological variants of radiation-induced and sporadic thyroid papillary carcinomas in children. Cancer Res 1997;57(9):1690-4. PMID:9135009.

25. Vaisman F, Corbo R, Vaisman M. Thyroid carcinoma in children and adolescents-systematic review of the literature. J Thyroid Res 2011;2011:845362. Doi:10.4061/2011/845362.Epub 2011 Sep 4.PMID:21904689;PMCID:PMC3166725.

26. Lee JH, Kim Y, Choi JW, Kim YS. The association between papillary thyroid carcinoma and histologically proven Hashimoto's thyroiditis: a meta-analysis. Eur J Endocrinol 2013;168(3):343-9. Doi:10.1530/EJE-12-0903. PMID:23211578.

27. Resende de Paiva C, Grønhøj C, Feldt-Rasmussen $U$, von Buchwald C. Association between Hashimoto's Thyroiditis and Thyroid Cancer in 64,628 Patients. Front Oncol 2017;7:53. Doi:10.3389/ fonc.2017.00053.PMID:28443243;PMCID:PMC5385456.

28. Cunha LL, Ferreira RC, Marcello MA, Vassallo J, Ward LS. Clinical and pathological implications of concurrent autoimmune thyroid disorders and papillary thyroid cancer. J Thyroid Res 2011;2011:387062. Doi:10.4061/2011/387062. PMID:21403889;PMCID:PMC3043285.
29. Hussein O, Abdelwahab K, Hamdy O, etal. Thyroid cancer associated with Hashimoto thyroiditis: similarities and differences in an endemic area. J Egypt Natl Canc Inst 2020;32(1):7. Doi:10.1186/ s43046-020-0017-9.PMID:32372240.

30. Zhang $L$, $L i ~ H, ~ J i ~ Q H$, et al. The clinical features of papillary thyroid cancer in Hashimoto's thyroiditis patients from an area with a high prevalence of Hashimoto's disease. BMC Cancer 2012;12:610. Doi:10.1186/1471-2407-12-610. PMID:23256514;PMCID:PMC3547693.

31. HarachHR,WilliamsED. Thyroidcancerandthyroiditis in the goitrous region of Salta, Argentina, before and after iodine prophylaxis. Clin Endocrinol (Oxf) 1995;43(6):701-6. Doi:10.1111/j.1365-2265.1995. tb00538.x.PMID:8736272.

32. Baumgarten $H$, Jenks $C M$, Isaza $A$, et al. Bilateral papillary thyroid cancer in children: Risk factors and frequency of postoperative diagnosis. J Pediatr Surg. 2020;55(6):1117-22. Doi: 10.1016/j.jpedsurg.2020.02.040.Epub 2020 Feb 27.PMID:32171533.

33. Chen J, Huang N, Ji Q, Wang Y, Zhu Y, Li D. Multifocal papillary thyroid cancer in children and adolescents: 12-year experience in a single center. Gland Surg. 2019;8(5):507-5. Doi:10.21037/ gs.2019.09.03.PMID:31741881;PMCID:PMC6842758.

34. Santini F, Marzullo P, Rotondi M, et al. Mechanisms in endocrinology: the crosstalk between thyroid gland and adipose tissue: signal integration in health and disease. Eur J Endocrinol 2014;171(4):R137-52. Doi:10.1530/EJE-14-0067. PMID:25214234.

35. Tamimi DM. The association between chronic lymphocytic thyroiditis and thyroid tumors. Int J Surg Pathol 2002;10(2):141-6. Doi:10.1177/106689690201000207. PMID: 12075407.

36. Cunha LL, Ferreira RC, Marcello MA, Vassallo J, Ward LS. Clinical and pathological implications of concurrent autoimmune thyroid disorders and papillary thyroid cancer. J Thyroid Res 2011;2011:387062. Doi:10.4061/2011/387062. PMID:21403889;PMCID:PMC3043285.

37. Chui MH, Cassol CA, Asa SL, Mete O. Follicular epithelial dysplasia of the thyroid: morphological and immunohistochemical characterization of a putative preneoplastic lesion to papillary thyroid carcinoma in chronic lymphocytic thyroiditis. Virchows Arch 2013;462(5):557-63. Doi:10.1007/s00428-013-1397-1.Epub 2013 Mar 27.PMID:23532502. 
38. Penko K, Livezey J, Fenton C, et al. BRAF mutations are uncommon in papillary thyroid cancer of young patients. Thyroid 2005;15(4):320-5. Doi:10.1089/thy.2005.15.320.PMID:15876153.

39. Gertz RJ, Nikiforov Y, Rehrauer W, McDaniel L, Lloyd RV. Mutation in BRAF and Other Members of the MAPK Pathway in Papillary Thyroid Carcinoma in the Pediatric Population. Arch Pathol Lab Med 2016;140(2)134-9. Doi: 10.5858/arpa.2014-0612-OA.PMID:26910217;PMCID:PMC8006595.

40. Geng J, Wang H, Liu $Y$, et al. Correlation between BRAF V600E mutation and clinicopathological features in pediatric papillary thyroid carcinoma. Sci China Life Sci 2017;60(7):729-38. Doi: 10.1007/s11427-017-9083-8.Epub 2017 Jun 15.PMID:28646474.

41. Hardee S, Prasad ML, Hui P, Dinauer CA, Morotti RA. Pathologic Characteristics, Natural History, and Prognostic Implications of BRAF ${ }^{\mathrm{V} 600 \mathrm{E}} \mathrm{Mu}-$ tation in Pediatric Papillary Thyroid Carcinoma. Pediatr Dev Pathol 2017;20(3):206-12. Doi: 10.1177/1093526616689628.Epub 2017 Feb 8.PMID: 28521635.

42. Viola D, Romei C, Elisei R. Medullary thyroid carcinoma in children. Endocr Dev 2014;26:20213. Doi:10.1159/000363165. Epub 2014 Aug 29.PMID:25231454. 